\title{
The muskrat (Ondatra zibethicus) as a laboratory animal*
}

\author{
JENNIFER A. NAGEL and ERNEST D. KEMBLE \\ Division of Social Sciences. Lniversity of Minnesota, Morris \\ Morris, Mimesota 56267
}

\begin{abstract}
Methods for the capture, maintenance, taming, and behavioral testing of wild-born muskrats (Ondatra zibethicus) are described. The muskrat is simple and inexpensive to maintain in the laboratory and seems suitable for behavioral research.
\end{abstract}

Despite repeated pleas for a more broadly based comparative psychology (Beach, 1950; Bitterman, 1960; Lockard, 1968), the albino rat remains the most frequently studied animal species in psychology. In view of this continuing trend, the behavioral study of other species within the large (35 families) and widely distributed Order Rodentia (Walker, 1968) should be of particular interest to comparative psychologists. Among the rodents whose behavior has not been studied in the laboratory to any great extent, the muskrat (Ondatra zibethicus) seems to be an apt choice. This commercially important fur bearer is widely distributed in North America and Europe and is quite abundant in some areas (Errington, 1963; Walker, 1968). In addition, there is an extensive literature describing various aspects of the muskrat's growth, reproduction, physiology, ecology, and field behavior (e.g., Beer \& Meyer, 1951; Butler, 1940; Errington, 1939) that has been ably summarized by Errington (1963) in his extensive (665-page) discussion of the muskrat.

During the past 2 years, we have captured, maintained, and studied six wild-born muskrats for various periods of time. We have found them simple to capture and maintain in the laboratory and have devised methods by which even the most intractable animals can be safely transported and tested. We also found that, despite their formidably large and sharp incisor teeth and initial defensiveness, a substantial number (four of six specimens) showed noticeable taming within 3-6 weeks in our laboratory. This report summarizes our experiences with this species.

\section{Capture ${ }^{1}$}

In areas heavily populated by muskrats (such as western Minnesota), population pressures frequently produce overland migration during the early spring months. Since muskrats are somewhat slow and clumsy on land. migrating specimens may be easily herded into an open cage by the judicious application of a broom or other long-handled prod and minimal agility. In areas having large muskrat populations. this may be a convenient method of obtaining specimens.2 Three (male) muskrats literally trapped themselves for our

*The authors would like to thank James Nelson and Thomas Straw for permitting us to live-trap three of the specimens. laboratory by falling into recessed window wells on our campus during nigration.

Our remaining three muskrats (one female, two males) were captured in a local slough. This was accomplished by placing large $(4.2 \times 11 \times 13$ in.) live traps (Havahart racoon traps) on the tops of two muskrat lodges. The traps were baited with small pieces of raw carrot, and additional pieces were scattered around the trap on the top of the lodge. No other precautions were necessary, and captures began within $48 \mathrm{~h}$.

\section{Housing and Maintenance}

The Ss were housed in $24 \times 16 \frac{12}{2} \times 13$ in. cages constructed of galvanized steel mesh in a constantly illuminated animal room maintained at $68^{\circ} .73^{\circ} \mathrm{F}$. Because muskrats are very effective gnawers and have strong claws, cages constructed entirely of metal are strongly advised. Also, since some Ss remain intractable in the laboratory, it is important that the cages be portable and self-contained so that they can be moved about the laboratory without opening.

A diet consisting of Purina Rat Chow (with adequate water supply), supplemented by small amounts of raw carrot and/or apple and occasional leafy green vegetables, seems quite adequate for the prolonged maintenance of muskrats. One mature male $S$ was maintained on this diet for over 1 year with no apparent ill effects. In addition, two immature muskrats (one male, one female) have developed into vigorous glossy adults on this diet. An adequate water supply is important for these largely aquatic Ss. In addition to sufficient supplies for drinking, an open water surface is important in maintaining adequate grooming and in allowing the moistening of the dry laboratory food. ${ }^{3}$ Heavy and stable pottery dishes (since Ss often perch on the rim) holding at least 1 qt of water are satisfactory if cleaned and refilled daily. We also place the Ss in a large $(60 \times 30 \times 28$ in.) galvanized sink containing $8-10$ in. of tap water and an overturned rat cage $(8 \times 10$ in.) to serve as a perch for $30-60 \mathrm{~min}$ per week. During these sessions, Ss engage in extensive bouts of grooming as well as swimming. Transfer of Ss to the sink is accomplished by placing the locked cage into the water, opening the cage door, and removing the cage after the $S$ swims out. This procedure is simply reversed to transfer $S$ back to the home cage.

\section{Taming}

Although all of the six muskrats we observed were quite defensive when captured. most (four of six) have shown a noticeable reduction in emotional responding to human Es within 3-6 weeks. Immediately after capture. Ss are fed small pieces of apple or carrot through the mesh of their home cage. When $S$ begins to accept food gently, rather than lunging at it, the cage door is slowly 


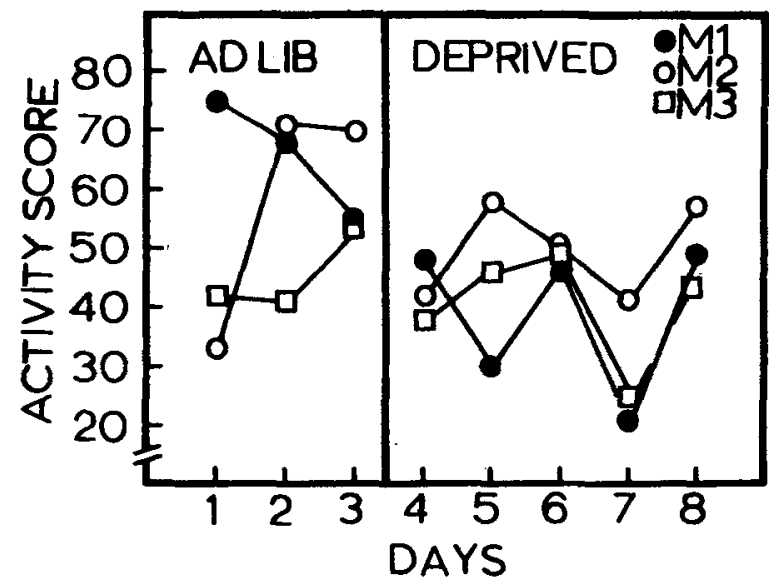

Fig. 1. Activity levels of three muskrats under ad lib and food-deprived conditions.

opened and food delivered by hand for several days or weeks. When $\mathrm{S}$ accepts this treatment calmly, it is gently stroked, first with a soft long-handled brush and then by hand. If $S$ continues to react calmly, it is slowly and gently grasped about the abdomen and lifted. Using this procedure, we have been able to handle safely three (one female, two male) of our six Ss. Two Ss have become sufficiently tame to allow $E$ to reach into their cages (only), and the remaining $S$ has remained intractably wild during 4 months' residence in the laboratory. Since muskrats move rather slowly when out of water, maintenance of even the most defensive $\mathrm{S}$ has posed few problems. In 2 years, handling by the Es has resulted in only two very superficial bite wounds.

\section{EXPERIMENT: ACTIVITY LEVELS}

Initially, we chose to measure locomotor activity of the muskrat under ad lib and food-deprived conditions. Such data are important for the design of behavioral investigations which may be seriously affected by strong competing behaviors (e.g., freezing) or lack of responsivness to a deprivation regimen (Bitterman, 1960). Since the muskrat is largely aquatic, swimming seemed to be the most appropriate activity measure. In addition, one of the male muskrats to be tested had remained thoroughly intractable in our lab (MR3), while the remaining two (MR1, MR2) had shown considerable taming. We were also interested in determining whether this "wildness" would importantly affect activity level.

\section{Subjects}

\section{Method}

The Ss were three adult (one female, two male) wild-born muskrats (Ondatra zibethicus) that had been acclimated to our laboratory for at least 1 month.

\footnotetext{
Apparatus

All testing was conducted in a large $(60 \times 30 \times 28$ in.) galvanized steel sink. The bottom of the sink was divided into four ( $30 \times 15$ in.) squares, and a small $(8 \times 10$ in.) upturned rat cage was placed in the center of each square to provide a perch. The sink was filled with tap water $\left(66^{\circ}-70^{\circ} \mathrm{F}\right)$ to a depth of $7 \mathrm{in}$.
}

\section{Procedure}

All Ss had been permitted to swim in this sink for $15.30 \mathrm{~min}$ daily for at least 3 weeks prior to the experiment. Activity measures were recorded for 20 min daily (8:30 p.m.-12:00 a.m.) for 8 consecutive days. Ss had continuous access to Purina Rat Chow and water, and were given one-quarter of an apple daily during the first 3 days of activity testing. On the remaining 5 days, Ss were deprived of all food for $23 \mathrm{~h}$ before each daily test.

For each activity test, the $S$ (and its home cage) was placed in the water-filled sink and released. S was allowed a 10-min adaptation period, 4 followed by 20 min observation of activity. Activity level was indexed by the number of squares entered (with at least half of S's body) during the 20-min observation period.

\section{Results}

The Ss' activity scores are separately depicted in Fig. 1. All animals engaged in substantial amounts of activity during these observations and did not show persistent or prolonged freezing. Even the highly intractable M3, though slightly less active, showed substantial activity scores. The inter-S variability of these scores does not exceed that which we have frequently observed during open-field tests with albino rats. Finally, the imposition of a 23 -h food-deprivation schedule produced a decrement in the activity levels of all Ss. This decline in activity was paralleled by a growing listlessness of Ss as deprivation continued. By the fifth day of deprivation, two of the three Ss (M1, M2) refused to eat when given access to food for $1 \mathrm{~h}$, and the deprivation schedule was terminated.

We also carried out some initial research on two-choice position discrimination and reversal. The animals readily acquired the original position discrimination, but failed to improve performance with successive reversals. These results are in need of further testing.

\section{DISCUSSION}

Our experience clearly indicates that muskrats may be easily captured (at least in areas of abundance) and maintained and tested in the laboratory. In addition, the maintenance and testing of this species requires relatively simple and inexpensive equipment which is either available or easily constructed in most laboratories. Moreover, the defensiveness displayed by muskrats upon capture quickly fades in most animals.

Although our experiments were restricted to a small number of Ss, the results do provide a number of suggestions for further research. First, it seems clear that muskrats do not respond well to prolonged food deprivation, at least under our laboratory conditions. ${ }^{5}$ A mild deprivation schedule (approximately $6 \mathrm{~h}$ ), however, combined with a highly palatable reward, such as apple, is effective in producing sustained operant behavior.

\section{REFERENCES}

Beach, F. A. The snark was a boojum. American Psychologist. $1950,5,115-124$

Beer, J. R., \& Meyer, R. K. Seasonal changes in the endocrine organs and behavior patterns of the muskrat. Journal of Mammology, 1951, 32, 173-191.

Bitterman, M. E. Toward a comparative psychology of learning. American Psychologist, 1960, 15, 704-712.

Butler, L. A quantitative study of muskrat food. Canadian Field Naturalist. 1940, 54, 37-40.

Errington, P. L. Observations on young muskrats in Iowa. Journal of Mammalogy, 1939, 20, 465-478. 
Errington, P. L. Muskrat populations. Ames: Iowa State University Press, 1963

Lockard, R. B. The albino rat: A defensible choice or a bad habit? American Psychologist, 1968, 23, 734-742.

Walker, E. P. Mammals of the World. (2nd ed.) Baltimore: Johns Hopkins Press, 1968.

\section{NOTES}

1. Since muskrats are extensively trapped for their fur, they are quite likely to be protected by game laws. Consultation with local conservation officers is strongly urged before trapping operations are begun.

2. Animals obtained in this way, however. are likely to be the less dominant members of their parent populations.

3 . Initial attempts to deliver water through spouted bottles were unsatisfactory. Although Ss would drink from the bottles if no other source of water was available, $\mathrm{Ss}^{\prime}$ fur tended to become matted within 3-4 days if swimming was not permitted. Extended observations (J.A.N.) indicate that grooming is a virtually invariable consequence of contact with open water.

4. This adaptation period is necessary because Ss typically engaged in almost continuous grooming for several minutes af ter being placed in water.

5. Muskrats commonly moisten Purina Rat Chow during consumption, which may reduce the amount eaten during a limited time. More rigorous food-deprivation schedules might be used with this species if a diet of succulent vegetables (e.g., raw carrot, lettuce) was provided.

(Received for publication August 15, 1973; revision received September 18, 1973.) 